\title{
Mammalian homologs of seven in absentia regulate DCC via the ubiquitin-proteasome pathway
}

\author{
Gang Hu, ${ }^{1,4}$ Sheng Zhang, ${ }^{5}$ Marc Vidal, ${ }^{6}$ Joshua La Baer, ${ }^{6}{\text { Tian } X u^{5}{ }^{5} \text { and Eric R. Fearon }}^{1,2,3,7}$ \\ Division of Molecular Medicine and Genetics, ${ }^{1}$ Departments of Internal Medicine, ${ }^{2}$ Human Genetics, and ${ }^{3}$ Pathology, \\ University of Michigan Medical Center, Ann Arbor, Michigan 48109-0638 USA; ${ }^{4}$ Departments of Pharmacology and \\ ${ }^{5}$ Genetics, Yale University School of Medicine, N ew Haven, Connecticut 06536-0812 USA; ${ }^{6}$ M assachusetts General \\ Hospital Cancer Center, Charlestown, Massachusetts 02129 USA
}

\begin{abstract}
DCC (deleted in colorectal cancer) is postulated to function as transmembrane receptor for the axon and cell guidance factor netrin-1. We report here that the DCC cytoplasmic domain binds to proteins encoded by mammalian homologs of the D rosophila seven in absentia (sina) gene, as well as D rosophila Sina. Sina has a critical role in $\mathbf{R 7}$ photoreceptor development and shows upward of $85 \%$ amino acid identity with its mammalian homologs (termed Siahs), but the function of the Sina/Siah proteins has not been defined. We sought, therefore, to characterize further their interaction with DCC. Immunofluorescence studies suggested the Sina/Siah proteins localized predominantly in the cytoplasm and in association with DCC. DCC was found to be ubiquitinated and the Sina/Siah proteins regulated its expression. Proteasome inhibitors blocked the effects of Sina/Siah on DCC, and the Sina/Siah proteins interacted with ubiquitin-conjugating enzymes (Ubcs). A mutant Siah protein lacking the amino-terminal Ubc-binding sequences complexed with DCC, but did not degrade it. The in vivo interaction between Sina/Siah and DCC was confirmed through studies of transgenic Drosophila lines in which DCC and Sina were ectopically expressed in the eye. Taken together, the data imply that the Sina/Siah proteins regulate DCC and perhaps other proteins via the ubiquitinproteasome pathway.
\end{abstract}

[Key Words: DCC; mammalian homologs; Drosophila sina gene; ubiquitin-proteasome pathway]

Received June 17, 1997; revised version accepted August 21, 1997.

DCC (deleted in colorectal cancer) was initially identified and cloned from a region of chromosome $18 q$ affected by allelic losses in upward of $70 \%$ of colorectal cancers (Fearon et al. 1990). Such losses are thought to indicate the existence of a tumor suppressor gene within the affected chromosomal region (Cavenee et al. 1983; Knudson 1993). DCC expression is reduced markedly or undetectable in the majority of colorectal cancer lines and primary tumors (Fearon et al. 1990; Itoh et al. 1993; Hedrick et al. 1994; Thiagalingam et al. 1996), and the loss of expression has been associated with poor prognosis (Shibata et al. 1996). Somatic mutations in DCC have been identified in some colorectal cancers, but the mechanisms underlying the loss of DCC expression in most cancers remain poorly understood, perhaps in part, because the gene spans $>1,350,000$ bp (Cho et al. 1994). Frequent DCC allelic losses and loss of its expression, as well as somatic mutations, have al so been seen in other malignancies (for review, see Cho and Fearon 1995; Fearon 1996; and Kolodziej 1997).

7Corresponding author.

E-MAIL efearon@mmg.im.med.umich.edu; FAX (313) 647-7979.
The primary product of the DCC gene is a 1447amino-acid transmembrane protein with four immunoglobulin-like and six fibronectin type III like extracellular domains and a 325-amino-acid cytoplasmic domain (Hedrick et al. 1994; Reale et al. 1994). Although DCC bears similarity to many immunoglobulin superfamily members, recent studies have established that DCC and closely related proteins comprise a unique subfamily (Kolodziej 1997). The DCC domain structure and sequence are most similar to that of neogenin (NGN), a protein whose expression is dynamical ly regulated in the developing nervous system and gastrointestinal tract of the chicken (Vielmetter 1994; M eyerhardt et al. 1997). Invertebrate DCC-related proteins have been identified recently, including the Caenorhabditis el egans U N C -40 and Drosophila Frazzled proteins (Chan et al. 1996; Kolodziej et al. 1996).

The specific cellular function of DCC is not known, but there are intriguing clues. Though expressed at low levels in many adult tissues, DCC is most abundant in brain tissue (Hedrick et al. 1994; Reale et al. 1994). DCC is expressed in developing neural tissues of vertebrate embryos (Pierceall et al. 1994a; Cooper et al. 1995) and 
has been implicated in neuronal differentiation of PC 12 cells (Lawlor and N arayanan 1992; Pierceal I et al. 1994b). Perhaps most significantly, recent studies have implied that DCC is a receptor for netrin-1, a vertebrate axon and cell guidance factor (Keino-M asu et al. 1996). The critical role of netrins, DCC, and DCC-related proteins in axon guidance and cell migration in the developing nervous systems of vertebrate and invertebrate organisms has been illustrated through a variety of cell biological and genetic studies (Chan et al. 1996; Kolodziej et al. 1996; Serafini et al. 1996; Fazeli et al. 1997; Kolodziej 1997)

To identify proteins that may regulate DCC or transduce signals via its unique cytopl asmic domain, we carried out yeast two-hybrid screens, using DCC cytoplasmic sequences as "baits." A homolog of the Drosophila seven in absentia (sina) gene was identified independently in both of our screens. Sina function is critical in R7 photoreceptor development (Carthew and Rubin 1990). Genetic studies indicate that Sina either functions downstream of other proteins in the sevenless (sev) pathway, including Ras, Raf, and M APK, or it functions in an independent pathway that together with the sev pathway specifies R7 formation (Fortini et al. 1992; Lai and Rubin 1992; Brunner et al. 1994; Chang et al. 1994, 1995; Dickson et al. 1995). Recently, defects in tramtrack (ttk) have been found to lead to supernumerary $R 7$ formation even in the absence of Sina (Lai et al . 1996; Y amamoto et al. 1996), suggesting Sina may down-regulate ttk. Despite the substantial interest in the Sev/Ras/MAPK pathway and R7 fate specification, the cellular function of Sina has not yet been defined. Here, we demonstrate that mammalian proteins highly related to Sina, Seven in absentia homologs (Siahs), as well as Drosophila Sina, bind to DCC. DCC was found to be ubiquitinated, and the Sina/Siah proteins appeared to mediate its degradation via proteasome-dependent mechanisms. Our findings indicate that the Sina/Siah proteins function in ubiquitin-mediated proteolysis and that they are candidate regulators of $\mathrm{DCC}$.

\section{Results}

Yeast two-hybrid studies identify Siah-2 as a DCC-binding protein

To identify cellular proteins that interact with the DCC cytoplasmic domain, we used a modified yeast two-hybrid system (Fields and Song 1989; Du et al . 1996; Vidal 1997). The full-length DCC cytoplasmic domain strongly activated reporter gene activity when fused to the GAL4 DNA-binding domain (data not shown). Therefore, we generated a series of constructs in which portions of the DCC cytoplasmic domain were fused to the GAL4 DNA-binding domain and characterized their activity. The GAL4-DCC4 construct lacked the prol inerich and acidic carboxyl terminus 55 amino acids of the DCC cytoplasmic domain and had mi nimal activity (Fig. $1 \mathrm{~A}$; data not shown), and it was used in the two-hybrid screens to identify interacting proteins.

Two different cDN A libraries were screened for inter- action with the DCC4 construct. One library (Alala I) was generated from CDNAs of murine gestational day 12-13 embryos, and the other library (Glio I) was constructed from CDNAs of glioblastoma xenografts propagated in immunocompromised mice. From each library, $1.5 \times 10^{6}$ transformants were obtained and initially selected for reporter-dependent 3-aminotriazole (3-AT) resistance. After further selection and retesting, nine cDN As from the Alala I screen and 13 cDN As from the Glio I screen scored repeatedly positive on all three reporter assays and demonstrated specific interaction with the DN A-binding domain-DCC 4 fusion. After sequence analysis, the 22 rescued cDN As were found to be derived from seven independent open-reading frames (ORFs) (data not shown). The only related cDN As identified independently in each screen were derived from overlapping fragments of a murine homolog (Siah-2) of the Drosophila sina gene (Della et al . 1993). One cDN A encoded amino acids 115-325 of Siah-2, and the other encoded amino acids 183-325.

As noted above, sina was identified because of its critical role in Drosophila R7 photoreceptor development (Carthew and Rubin 1990). Little is known about the 314-amino-acid Sina protein other than it contains an amino-terminal cysteine-rich domain, similar to the socalled $\mathrm{C}_{3} \mathrm{HC}_{4}$ or RIN G zinc finger domain (Saurin et al. 1996). Three highly conserved murine Siahs, termed Siah-1A, Siah-1B, and Siah-2, have been described (Della et al. 1993). There are two human homologs, termed Si ah- 1 and Siah-2, displaying 96\%-99\% amino acid identity with their murine counterparts and $\sim 77 \%$ identity with one another (Nemani et al. 1996; Hu et al. 1997). Drosophila Sina is extremely well conserved with mammalian Siahs, with $\sim 85 \%$ identity between Sina and Siahs over their carboxy terminal 270 amino acids (Della et al. 1993; Hu et al. 1997). Interaction between the DCC cytoplasmic domain and human Siahs was demonstrated in the yeast two-hybrid system (Fig. 1A; data not shown). Given the conservation between Siahs and Sina, we expected that DCC would interact with Sina. This interaction was demonstrated readily (Fig. 1A). No interactions between the Sina/Siah proteins and irrelevant proteins were observed in the two-hybrid assay (Fig. 1A; data not shown). DCC interacted with the carboxy-terminal 140 amino acids of the Sina/Siah proteins (Fig. 1B).

\section{In vitro binding of Sina and DCC}

The interaction betwen DCC and Sina was al so studied in an in vitro binding assay. Glutathione S-transferase (GST) fusion proteins containing various portions of the DCC cytoplasmic domain were expressed in Escherichia coli and affinity purified. Lysates were prepared from COS-1 cells that had been transfected transiently with an expression vector encoding a full-length Drosophila Sina protein tagged with a c-M yc epitope tag at its amino terminus. The lysates were then incubated with the various GST-DCC fusion proteins or control proteins. Proteins recovered on a gl utathione-Sepharose matrix were washed extensively, el uted, and studied by Western blot- 

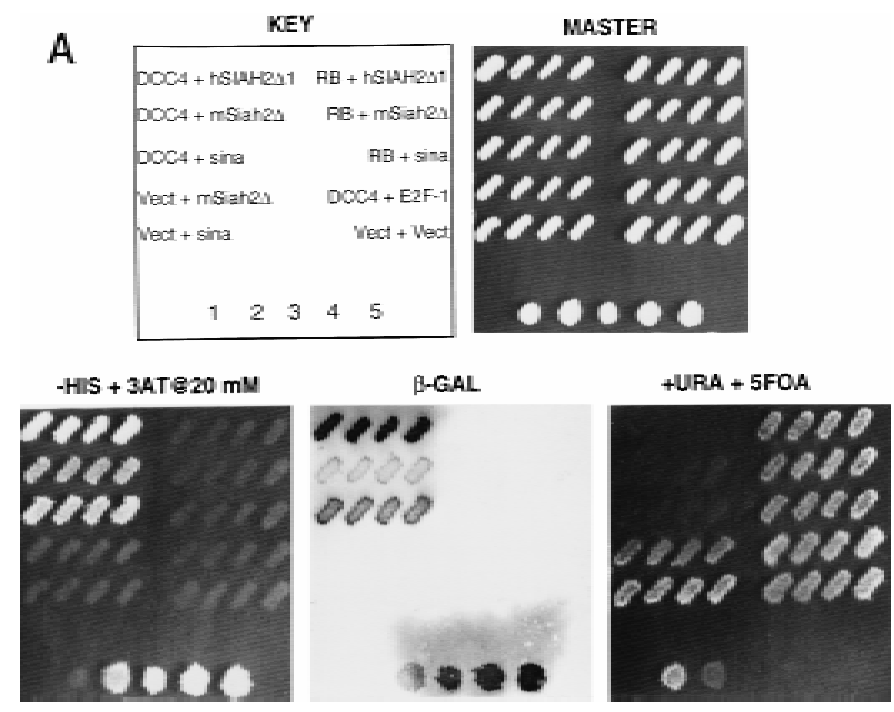

Figure 1. Yeast two-hybrid studies of DCC, Sina, and mammalian Sina homologs (Siahs). (A) Yeast two-hybrid interaction between DCC and Sina/Siah proteins. Yeast strain MaV103 was cotransformed with the indicated GAL4 DNA-binding (DB) and activation domain (AD) fusions. DB fusions were GA L4-DCC4 (DCC4, amino acids 1120-1392) or GA L4DB-p105-RB (RB; amino acids 302-908). AD fusion proteins contained human Siah2 $\Delta 1$ (amino acids 103-324), mouse Siah2 $2 \Delta$ (amino acids 115-325), Drosophila Sina (amino acids 115-314), or human E2F-1 (amino acids 159-437) sequences. Y east transformants were initially grown on permissive SC-Leu-Trp (master) plates. Reporter assays were performed by replica plating the master plate onto a SC-Leu-Trp-His plate containing 20 mM 3-AT (-His+3AT 20 mm); Hybond N + membrane on SC-Leu-Trp plate for $\beta$-Gal assay ( $\beta$-Gal); and SC-Leu-Trp plate containing 0.2\% 5-fluoro-orotic acid (+URA +5FOA). Positive two-hybrid interactions are indicated by growth on the -HIS + 3AT plate, $\beta$-gal activity, and lack of growth on +URA + 5FOA plate. Controls 1-5 are derived from the same yeast strain cotransformed with (1) pPC97CYH+pPC86; (2) DB-RB+AD-E2F1; (3) DB-Fos+AD-Jun; (4) Gal4+pPC86; and (5) DB-E2F1+AD-DP1. Equival ent expression of the majority of $D B$ and $A D$ fusions was verified by Western blot analysis. (B) Minimal region of Siah-2 needed for interaction with DCC in the yeast two-hybrid assay. Studies to define the Siah-2 sequences were performed as described in A.

ting with a c-Myc antibody. DCC fusion proteins containing nearly the full-length human DCC cytoplasmic domain (i.e., GST /DCC-B) or the Xenopus DCC cytoplasmic domain (GST / DCC-XL) were readily able to capture Sina protein. Fusion proteins with substantial deletions of the DCC cytoplasmic domain and nonspecific control proteins (e.g., GST-p16) failed to bind Sina (Fig. 2A). Consistent with the two-hybrid results described above, a truncated Sina protein lacking the carboxy-terminal 115 amino acids failed to bind to DCC (Fig. 2A). In vitro binding and yeast two-hybrid studies indicated DCC amino acids 1203-1364 were needed for binding to Sina/Siah (Fig. 2B).

\section{DCC and Sina proteins colocalize}

We sought to establish further the interaction between the DCC and Sina/Siah proteins and undertook immunofluorescence studies to determine if the proteins colocalized in transfected tissue culture cells. Using confocal microscopy, we found that the full-length DCC protein exhibited a membrane local ization in Drosophila S2 cells (Fig. 3A), whereas a cDNA encoding only the DCC cytoplasmic domain yielded diffuse staining throughout the cytoplasm (Fig. 3B). Though previous studies had suggested that Sina was predominantly a nuclear protein (Carthew and Rubin 1990), wefound that a full-length Sina protein tagged at its amino terminus with a c-M yc epitope local ized predominantly in cytoplasmic particl es (Fig. 3C). Studies of epitope-tagged Sina and human Siah-1 proteins in Chinese hamster ovary $(\mathrm{CHO})$ cells al so indicated a cytoplasmic localization for the Sina/Siah proteins (data not shown). Deletion of the carboxy-terminal 115 amino acids of Sina abrogated its localization to the cytoplasmic particles, resulting in a more uniform distribution of the truncated protein throughout the cell (Fig. 3D).

In S2 cells expressing both full-length DCC and Sina, we found that Sina protein was many times localized to the membrane (Fig. 3E), consistent with an interaction between DCC and Sina. In cells coexpressing Sina and the cytoplasmic form of DCC, Sina and DCC demonstrated colocal ization in cytopl asmic particles (Fig. 3F). The col ocal ization required specific interaction between DCC and Sina because a further truncated form of the DCC cytoplasmic domain, lacking the Sina-binding sequences, no longer colocalized with Sina (Fig. 3G). Colocalization of DCC and Sina in cytoplasmic particles was al so observed following transfection of COS-1 monkey kidney cells (Fig. 3H). However, in Drosophila S2 and COS-1 cells cotransfected with DCC and Sina, only a fraction of the cells expressed DCC, despite the fact that a sizeable proportion of the cells expressed Sina (data not shown). Because DCC was well-expressed on 
Hu et al.
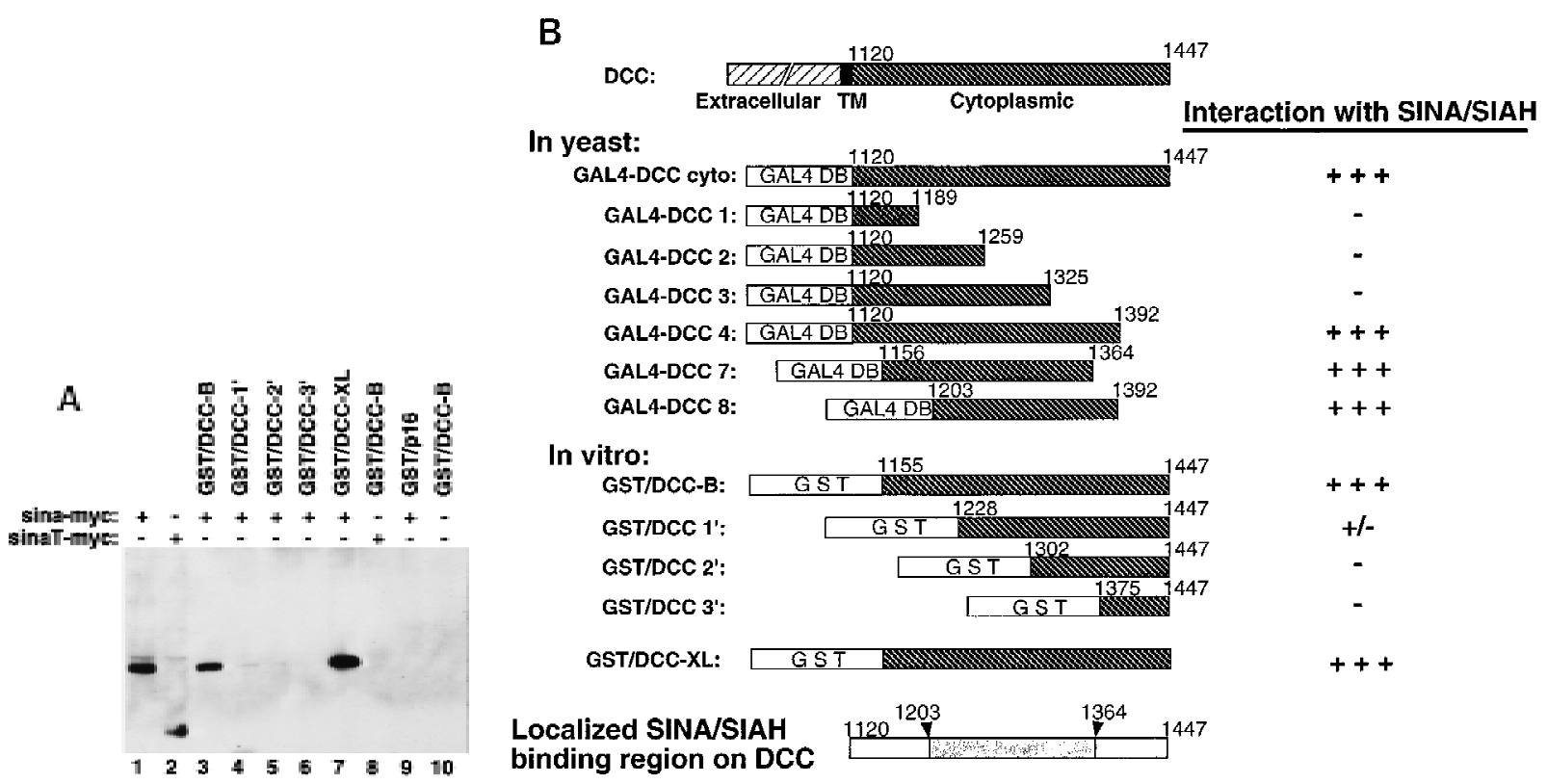

Figure 2. Association of DCC and Sina in vitro. (A) In vitro binding assay for DCC and Sina. Lysates of COS-1 cells transfected with a c-M yc epitope-tagged sina cDN A (Sina-myc, lanes 1,3-7,9), a carboxy-terminal truncated form (SinaT-Myc, Ianes 2,8), or empty expression vector (lane 10) were incubated with $10 \mu \mathrm{g}$ of each affinity-purified GST fusion protein, including GST / DCC-B (amino acids 1155-1447, Ianes 3,8,10); GST / DCC-1' (amino acids 1228-1447, Iane 4); GST / DCC-2' (amino acids 1302-1447, Iane 5); GST / DCC-3' (amino acids 1375-1447, lane 6); GST/DCC-XL (cytoplasmic domain of Xenopus DCC, lane 7); and GST/p16 (human p16 cyclin kinase inhibitor, lane 9). GST fusion proteins were recovered by incubation with glutathione-Sepharose beads, and bound proteins were rel eased and analyzed by Western blot analysis, using the c-M yc monoclonal antibody 9E10.2 and ECL. Lanes 1 and 2 are COS-1 Iysates of Sina-Myc and SinaT-Myc, and represent the abundance of the Sina proteins in one-third of the lysate used for each in vitro binding experiment. (B) M apping of the minimal region of the DCC cytoplasmic domain required for binding to Sina/Siah in yeast and in vitro.

its own (see below), the findings indi cated that Sina/Siah proteins might affect DCC expression.

\section{Siah proteins regulate DCC protein expression}

To determine whether the Sina/Siah proteins regulated DCC expression, we assessed their effects on DCC expression using Western bl ot analysis. COS-1 and $\mathrm{CHO}$ cells were cotransfected with mammalian expression vectors containing DCC and SIAH CDNAs (Fig. 4A). After transfection, DCC protein levels were assessed. In both COS-1 and CHO cells, comparison with the control transfection revealed that DCC expression levels were reduced markedly when full-length DCC (DCC-FL) was coexpressed with Siah-1 or Siah-2 (Fig. 4B). Similar findings were obtained when DCC-FL was coexpressed with Sina (data not shown).

Ribonuclease protection assays demonstrated that DCC transcript levels were not affected by Siah expression. Moreover, Siah expression failed to affect the expression of a truncated DCC protein (DCC-T) lacking most of the DCC cytoplasmic domain (Fig. 4B). The expression of a control luciferase construct was not affected by Siahs (data not shown). M utant forms of Siah-2 lacking either the carboxy-terminal DCC-binding se- quences or amino-terminal sequences failed to downregulate DCC expression (Figs. 4A ,B). Studies with a vector encoding only the DCC cytoplasmic domain demonstrated that DCC need not be expressed on the cell surface to be down-regulated by Siahs (Fig. 4C). Furthermore, a construct expressing an anti-sense SIAH-2 cDNA led to an increased level of full-length DCC expression in COS-1 cells, but had no effect on the expression of the truncated form of DCC (Fig. 4D), suggesting that the anti-sense SIAH-2 transcripts inhibited the activity of endogenous Siah-2 on DCC expression in COS-1.

To assess the effects of the Sina/Siah proteins on DCC protein turnover, COS-1 cells were cotransfected with DCC and SIAH-2 CDNAs, and after transfection, the cells were metabolical ly labeled with a 1-hr pulse of ${ }^{35} \mathrm{~S}-$ labeled amino acids. Following varying chase periods, DCC proteins were collected by immunoprecipitation, separated by SDS-PAGE, and fluorography carried out. In cells transfected with full-length DCC and the control vector, the half-life of DCC protein was $\sim 24 \mathrm{hr}$ (Fig. 5A). In contrast, cotransfection with a SIAH-2 CDNA re duced the half-life of DCC to $\sim 6 \mathrm{hr}$. As expected, SI AH-2 had no effect on the half-life of the DCC-T, al though we did note that the DCC-T had a decreased half-life compared with full-length DCC (Fig. 5B). Taken together, the 

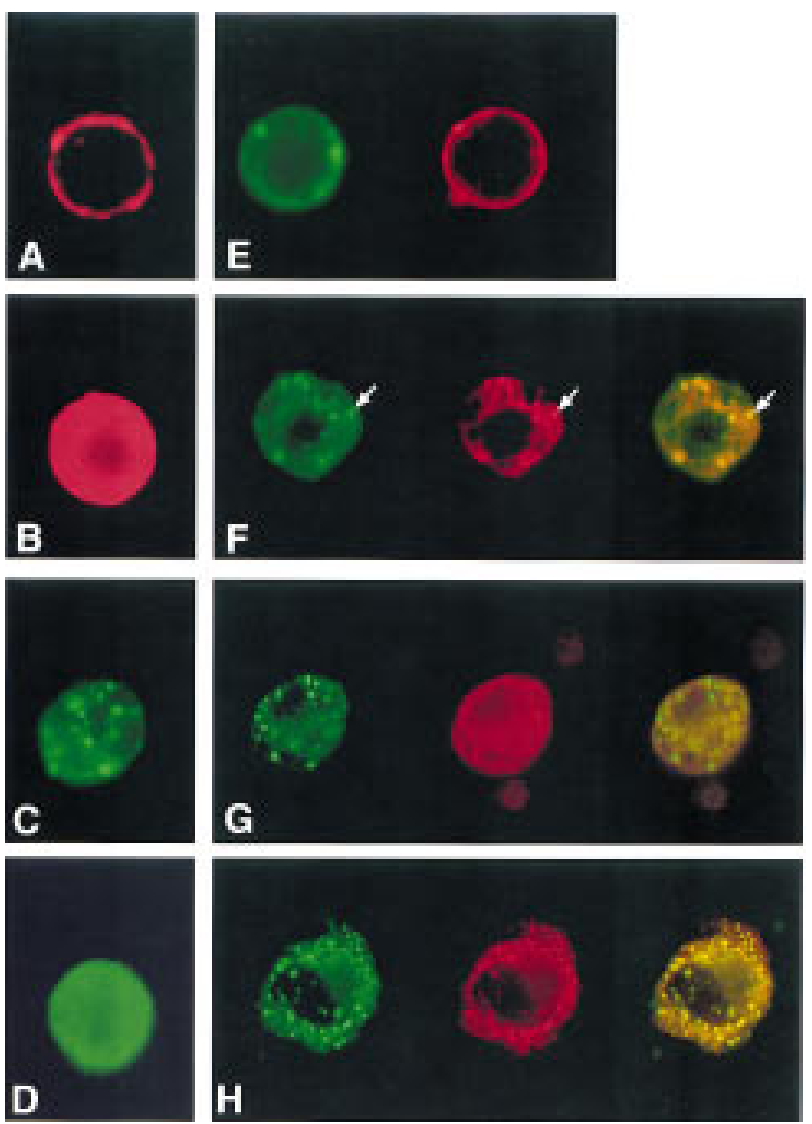

Figure 3. Confocal microscope images of DCC and Sina localization in Drosophila S2 cells and monkey kidney COS-1 cells. Constructs encoding full-length DCC protein $(A, E)$, the DCC cytoplasmic domain $(\mathrm{B}, \mathrm{F}, \mathrm{H})$ and carboxy-terminal truncated form of the DCC cytoplasmic domain $(G)$ were expressed al one $(A, B)$ or together with Sina $(E-H)$ in Drosophila S2 cells $(A-G)$ or COS-1 cells $(\mathrm{H})$. Full-length Sina (C) or a carboxy-terminal truncated Sina protein (D) were al so expressed al one in Drosophila S2 cells. The expression of DCC (red) and Myc-tagged sina (green) was detected by immunofluorescence double staining with a DCC rabbit polyclonal antibody and a C-M yc monoclonal antibody, foll owed by Texas red-conjugated goat anti-rabbit and FITC-conjugated goat anti-mouse secondary antibodies. The images were captured by confocal microscopy, and pseudo-coloring was performed using the Adobe Photoshop software program. Colocalization of the fluorescence signals was demonstrated by yellow signals when the red and green images were overlaid (e.g., indicated by arrows in F).

findings imply that the Siahs regulate DCC protein stability through interaction with the DCC cytoplasmic domain.

U biquitin-proteasome pathway in Sina/Siah regulation of DCC expression

The ubiquitin-proteasome pathway regulates degradation of many proteins (Varshavsky 1992; Ciechanover 1994; Goldberg 1995), and we sought to determine whether Siahs promoted DCC degradation through this pathway. COS-1 cells were cotransfected with DCC and Siah-2 or a control vector. After transfection, cells were subjected to a 6-hr treatment with various protease inhibitors, and DCC expression was then studied by Western blot analysis. The peptide al dehyde M G132, a potent inhibitor of proteasome function (Rock et al. 1994; Palombella et al. 1994), inhibited the effect of Siah-2 on DCC expression, whereas none of the other protease inhibitors tested displayed such activity (Fig. 6A; data not shown). The other inhibitors studied included calpain inhibitor II, a calcium-dependent cysteine protease inhibitor; E64, another potent cysteine protease inhibitor; chymostatin, a chymotrypsin inhibitor; AEBSF, a serine protease inhibitor; and leupeptin, a serine (and thiol ) protease inhibitor. Additional studies demonstrated that 5$20 \mu \mathrm{M}$ concentrations of MG132 were sufficient for bl ocking the effects of Siah-2 on DCC stability in COS-1 cells (Fig. 6B). Such concentrations are within the range in which M G132 specifically inhibits proteasome activity in cells (Palombella et al. 1994).

U biquitination and polyubiquitination target proteins for degradation by the proteasome (Varshavsky 1992; Ciechanover 1994; Goldberg 1995). To examine whether DCC is ubiquitinated in cells, DCC was coexpressed in COS-1 cells along with a construct encoding a c-M yc epitope-tagged yeast ubiquitin (c-M yc/Ub). Lysates were prepared from the cells and DCC protein was collected by immunoprecipitation. Following electrophoresis, the immunoprecipitates were studied first by Western blot anal ysis with an antibody agai nst the c-M yc epitope. Following cotransfection of the cells with the DCC and c$\mathrm{Myc} / \mathrm{Ub}$ constructs, the c-M yc-epitope-tagged ubi quitin was linked coval ently to DCC proteins of $\sim 220 \mathrm{kDa}$ or greater (Fig. 7A, left panel, lane 2, data not shown). Increased levels of ubiquitin were detected on DCC when the cells were cotranfected with expression constructs for DCC, c-M yc/Ub, and Siah-2 and treated with M G132 (Fig. 7A, left panel, lane 3). Subsequent Western analysis reveal ed that equivalent amounts of DCC protein were present in all lanes. The findings indicate that DCC can be ubiquitinated in cells.

Given that the Sina/Siah proteins appear to regulate DCC via the ubiquitin-proteasome pathway, we sought to obtain more detailed insights into their function. We undertook studies with the yeast two-hybrid system using full-length Drosophila Sina fused to the GAL4 DNAbinding domain to screen a Drosophila SL2 CDNA Iibrary. Roughly $0.5 \times 10^{6}$ transformants were obtained and selected for reporter-dependent 3-AT resistance. Further selection and retesting yielded three independent cDNAs that demonstrated specific interaction with Sina. Sequence analysis reveal ed that one of the three clones encoded a Drosophila homolog of the Saccharomyces cerevisiae Ubc9 (ubiquitin-conjugating) protein (Seufert et al. 1995). Additional studies were undertaken to characterize the interaction of Sina/Siah proteins with U bc9 homologs. Similar to the interaction between sina and the Drosophila Ubc9 homolog, both human Si ah- 1 and Siah- 2 interacted in the yeast two-hybrid sys- 
Hu et al.
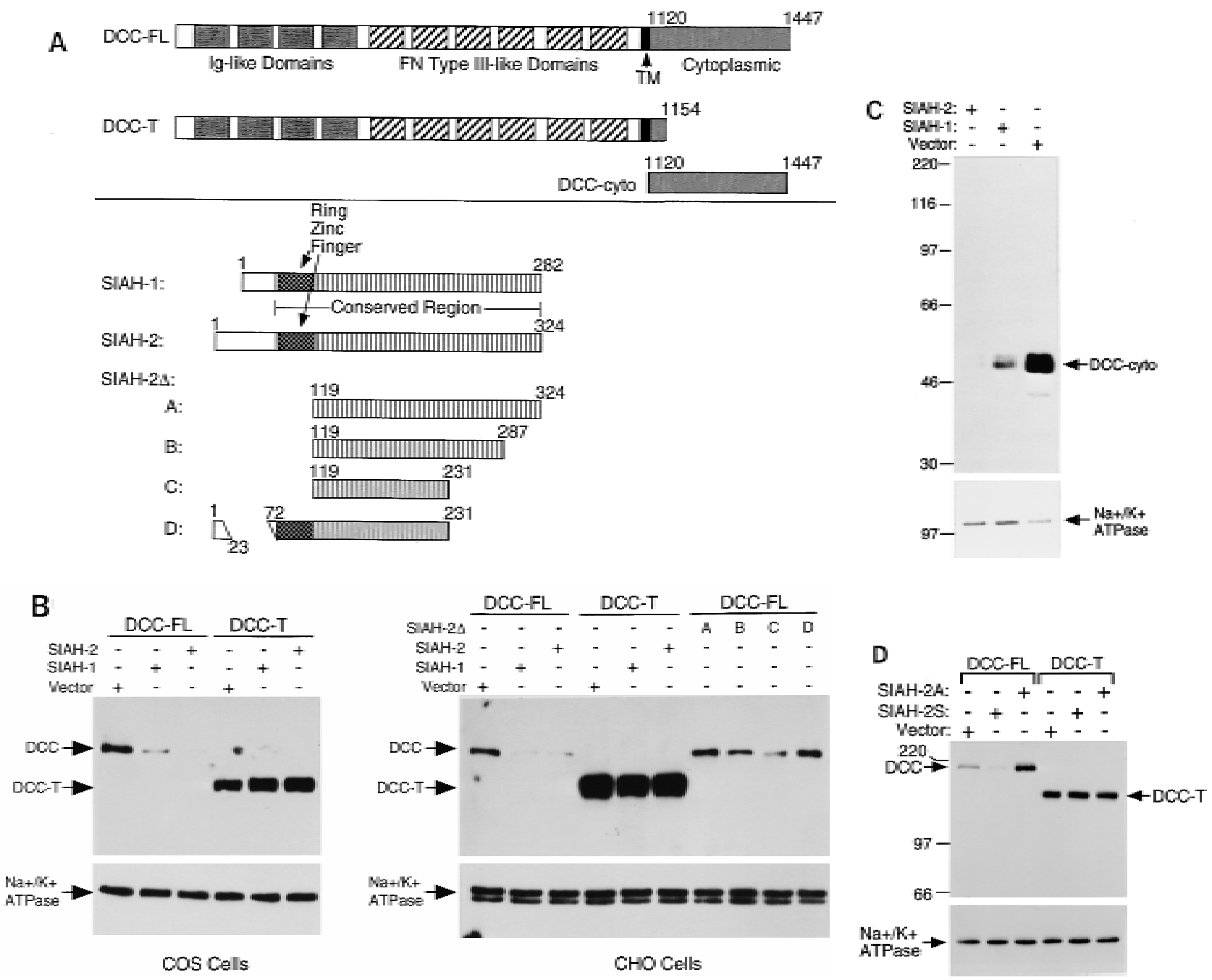

Figure 4. Siahs regulate DCC expression in mammalian cells. (A) Schematic representation of DCC and Siah proteins encoded by the cDN A constructs. The truncated forms of Siah- 2 are indicated as Siah-2 $\Delta \mathrm{A}$, Siah $\Delta \mathrm{B}, \mathrm{Siah} \Delta \mathrm{C}, \operatorname{Siah} \Delta \mathrm{D}$. (B) Siah-1 and Siah-2 regulate the expression of full-length DCC (DCC-FL), but not that of a truncated form lacking most of the DCC cytoplasmic domain (DCC-T). As indicated, COS-1 and CHO cells were cotransfected with CDN As for DCC-FL or DCC-T and Siah-1, Siah-2, Siah-2 's's, or the control (empty) expression vector. Forty-eight hours after transfection, Western blot analysis was carried out on the cell lysates, using DCC extracellular domain monoclonal antibody G92-13 and ECL reagents. The membranes were then stripped and ECL-Western blot analysis was performed with a polyclonal antibody against $\mathrm{N} \mathrm{a}^{+} / \mathrm{K}^{+}$ATPase to verify the loading. (C) The expression of a cytoplasmic form of DCC is regulated by Siahs. A CDN A encoding the DCC cytoplasmic domain (DCC-cyto) was cotransfected with Siah-1, Siah-2, or the control CMV expression vector (vector). The Western bl ot analysis of DCC and $\mathrm{N} \mathrm{a}^{+} / \mathrm{K}^{+} \mathrm{ATPase}$ was performed as above, except that ECL-Western blot analysis of DCC was carried out with DCC cytoplasmic domain monoclonal antibody G97-449. The mobility of molecular weight markers is indicated at the left. (D) Antisense SIAH-2 expression in COS-1 cells results in increased expression of DCC-FL, but has no effect on DCC-T expression. The studies were performed with the indicated vectors as described in B.

tem with a human U bc9 homolog cloned previously (Kovalenko et al. 1996) (Fig. 7B). Truncation of the aminoterminal 114 amino acids of Sina, including its RING finger domain, inhibited its interaction with Drosophila Ubc9 (Fig. 7B; data not shown), suggesting the aminoterminal regi on of Sina is critical for the interaction with U bc9. This finding complements our prior observation that the amino-terminal region of Siah-2 is not needed for binding to DCC in yeast but is critical for down- regulation of DCC expression in mammalian cells (Fig. $4 \mathrm{~A}, \mathrm{~B})$. Furthermore, following their expression in $\mathrm{CHO}$ cells, we were able to coprecipitate full-length DCC and an epitope-tagged mutant form of Siah-1 lacking the amino-terminal U bc-binding sequences (Fig. 7C). As expected, Siah-1 did not coprecipitate with a cytoplasmic domain truncated form of DCC (DCC-T). These findings establish that Sina/Siah proteins can complex with DCC in cells. 
A

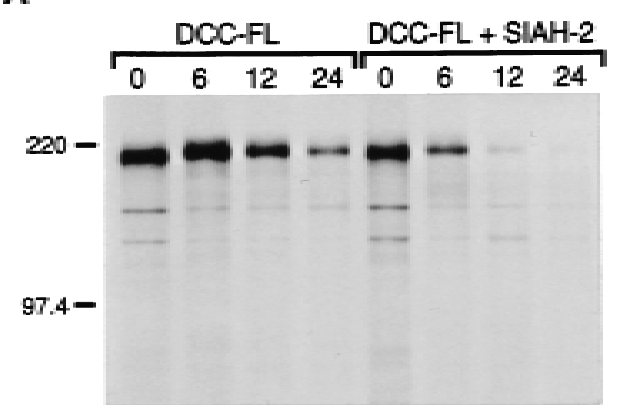

B

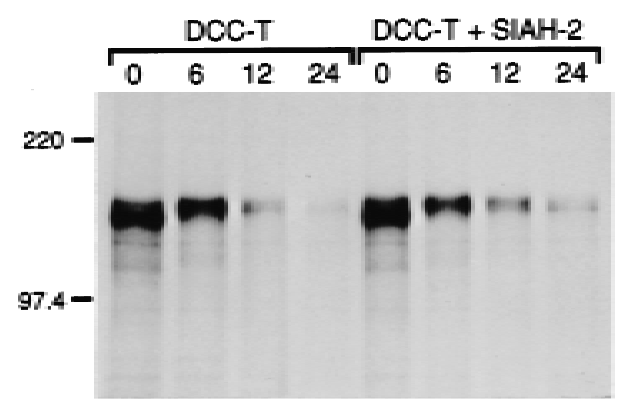

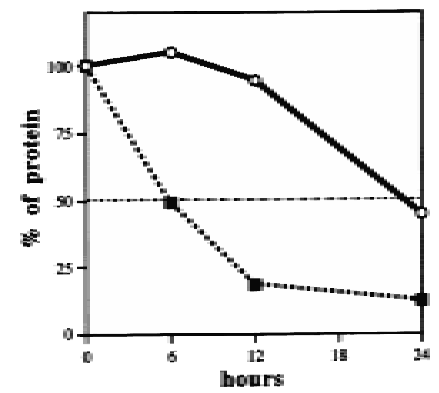

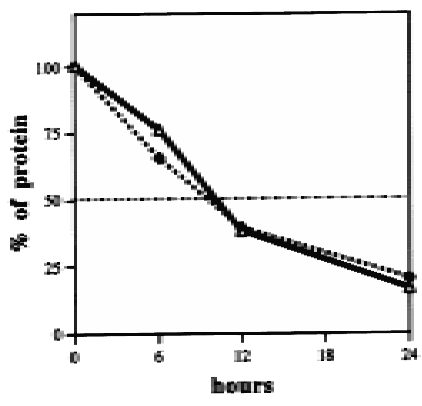

Figure 5. Siah-2 decreases DCC half-life via its cytoplasmic domain. A pulse-chase analysis was undertaken to determine the half-life of DCC proteins in the presence or absence of Siah-2. COS-1 cells were cotransfected with expression constructs encoding full-length DCC (DCC-FL, A) or a truncated form of DCC lacking the majority of the cytoplasmic domain (DCC-T, B) and human Siah-2 (Siah-2) or the control expression vector. Forty-eight hours after transfection, the cells were pulse-labeled for $1 \mathrm{hr}$ with a $\left[{ }^{35} \mathrm{~S}\right]$ methione/cysteine mix, chased with cold methione/cysteine for the indicated times, and then lysed. DCC proteins were immunoprecipitated with polyclonal antibody 645 and analyzed by SDS-PAGE and fluorography (left). The mobility of molecular weight markers is indicated. The autoradiographic signals of the 190 kD DCC protein were quantitated by densitometry and the data were plotted as a function of time (right) (O) DCC-FL; (ם) DCC-FL and Siah-2 in A. $(\triangle)$ DCC-T; $(\bullet)$ DCC-T and Siah-2 in B.
Interaction between DCC and Sina in the developing Drosophila eye

We next generated transgenic Drosophila lines in which the human DCC gene was expressed in the developing eye under control of sev promoter/enhancer elements (sev-DCC). Although no obvious phenotype was seen in several independent transgenic lines carrying one copy of sev-DCC, eye phenotypes in flies with multiple copies of sev-DCC were evident. Scanning el ectron micrograph studies revealed that the two copy $(2 x)$ sev-DCC flies had moderately rough eyes and four copy $(4 x)$ sev-DCC flies had very rough eyes (Fig. 8; C-F). Eyes of sev-DCC flies were smaller than normal, with apparent fusion of ommatidia and bristle defects. A pical sections through adult retinae demonstrated defects in the orientation of the ommatidia with respect to dorsal/ventral and/or anterior/posterior axes (Fig. 9). sev-DCC flies also had fu-

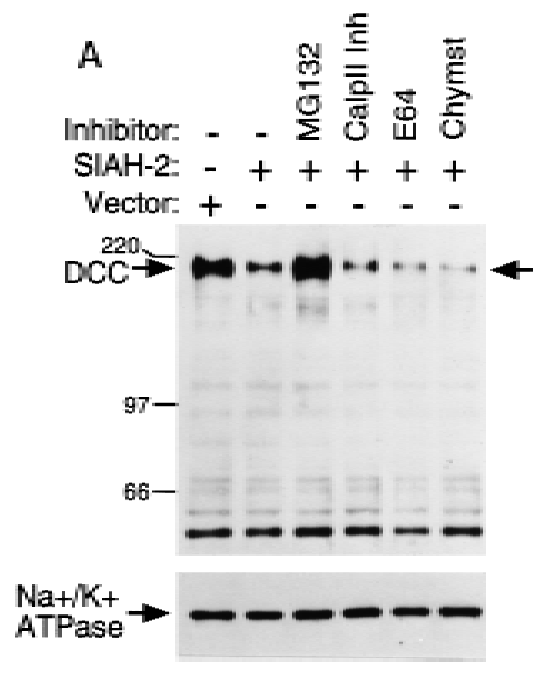

B

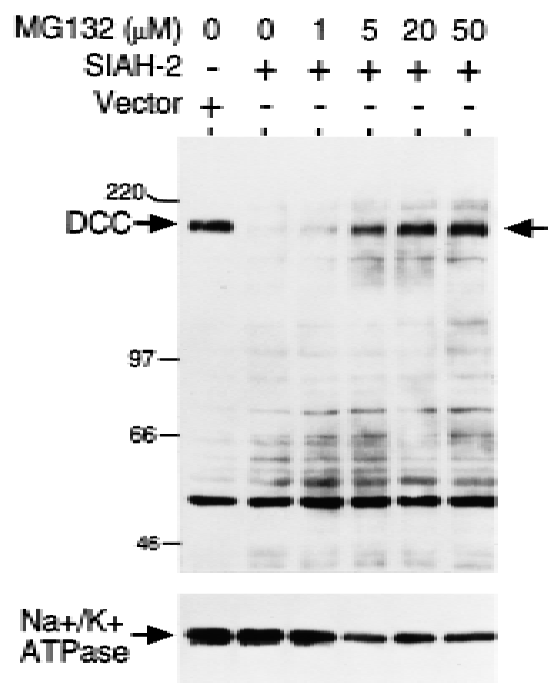

Figure 6. Effects of Siah-2 on DCC expression are blocked by the proteasome inhibitor MG132. (A) Forty-eight hours after co-transfection of COS-1 cells with expression vectors encoding full-length DCC and Siah-2 or a control vector, cells were incubated with dimethyl sulfoxide (DMSO; -inhibitor lane) or various protease inhibitors for $6 \mathrm{hr}$ at $37^{\circ} \mathrm{C}$. The final concentrations of the inhibitors in the media were: MG132, $20 \mu \mathrm{M}$; Calpain inhibitor II (Calp II Inh), $20 \mu \mathrm{m}$; E64, 50 $\mu \mathrm{m}$; chymostatin (Chymst), $50 \mu \mathrm{m}$. After incubation, Iysates were prepared and the levels of DCC expression were detected by Western blot analysis using DCC extracellular domain monoclonal antibody G92-13 and $E C L$ reagents. $M$ embranes were then stripped and Western blotted with an antibody against $\mathrm{N} \mathrm{a}^{+} / \mathrm{K}^{+}$ATPase to verify loading. M obility of molecular weight markers is indicated at the left. (B) Dose response of MG132 inhibition of Siah-2-mediated DCC degradation. The studies were carried out as described in A. 
sion of ommatidia arising apparently, at least in part, from defects in formation of pigment cells at the boundaries between adjacent ommatidia. Only $\sim 30 \%$ of the ommatidia were surrounded fully by pigment cells in the $2 \times$ sev-DCC flies (Fig. 9). Interestingly, we noted that $\sim 10 \%$ of the ommatidia in the $2 \times$ sev-DCC flies lacked R7 photoreceptor cells (Fig. 9C,D), and in $4 \times$ sev-DCC flies, upward of $60 \%-80 \%$ of ommatidia were missing
R7 cells (Fig. 9E,F). In a small subset of ommatidia of sev-DCC flies, loss of outer photoreceptor cells was al so noted (Fig. 9D).

As noted above, loss of R7 cells is the predominant eye defect seen in flies with sina loss-of-function mutations, although some outer photoreceptors are al so lost in flies with strong allel es (Carthew and Rubin 1990). Therefore, we speculated that ectopic expression of human DCC in

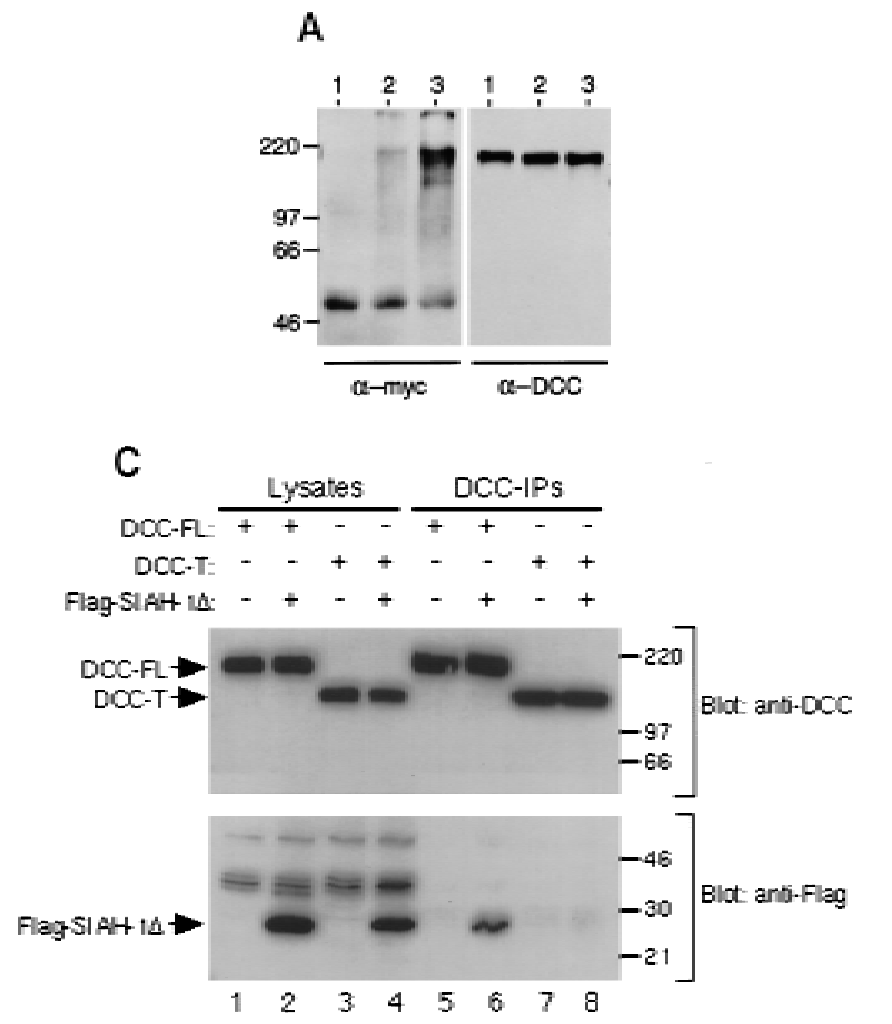

B

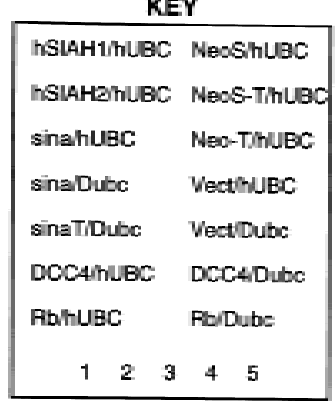

3ATE20mM (-His)

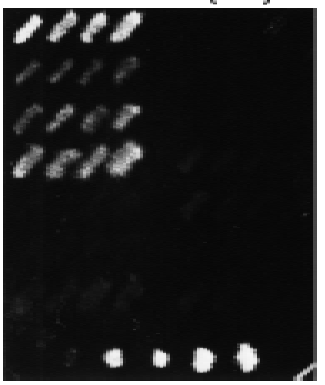

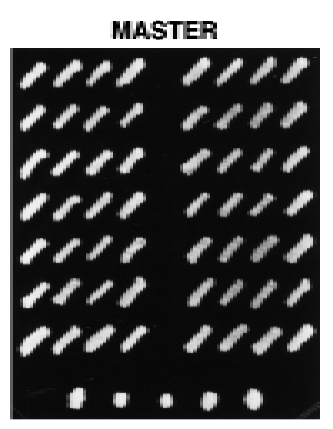

5FOAE0.2\%

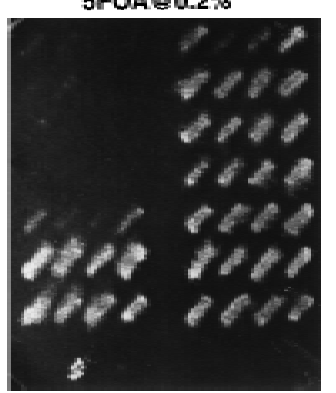

Figure 7. DCC, Sina/Siah, the ubiquitin pathway, and stable interactions between DCC and a mutant form of Siah-1. (A) DCC is ubiquitinated. COS-1 cells were cotransfected with vectors encoding full-length DCC (lanes 1-3), a c-M yc epitope-tagged yeast ubiquitin (Ianes 2,3), Siah-2 (lane 3), and control vector (lane 1). Forty-eight hours after transfection, the cells were treated for 6 hr at $37^{\circ} \mathrm{C}$ with $20 \mu \mathrm{M} \mathrm{MG} 132$ dissolved in DMSO (lane 3) or the same concentration of DMSO (lane 1 and 2). DCC proteins were collected by immunoprecipitation with DCC polyclonal antibodies 645 and 723 . The immunoprecipitates were electrophoresed and Western blot analysis was performed to identify DCC proteins to which the c-Myc tagged ubiquitin polypeptide had been coval ently attached, using C-M yc monoclonal antibody 9E10.2 and ECL reagents (left panel). After stripping the bl ot, the abundance of DCC protein in each lane was determined by Western blot analysis with DCC extracellular domain monoclonal antibody G92-13 and ECL reagents (right panel). The mobility of molecular weight markers is indicated at the left. (B) Sina and human Siah homologs interact with ubiquitinconjugating ( $\mathrm{Ubc}$ ) proteins in the yeast two-hybrid system. DB fusion constructs and AD fusion constructs were cotransformed into yeast strain MaV103. (DB fusions) Full-length human Siah1 and Siah2 (hSiah1 and hSiah2); full-length Drosophila Sina (sina); aminoterminal truncated Sina (sinaT); human DCC cytoplasmic domain (DCC4, amino acids 1120-1392); human retinoblastoma protein $(\mathrm{Rb})$; truncated form of human neogenin cytoplasmic domain ( $\mathrm{N} \mathrm{eo-T}$ ); spliced form of human neogenin cytoplasmic domain ( $\mathrm{N}$ eoS); and the truncated and spliced form of human neogenin cytoplasmic domain (N eoS-T). (AD fusions) Human homolog of yeast UBC9 (hUBC) and Drosophila homolog of UBC9 (Dubc). Y east transformations, growth, reporter gene studies, and interaction controls 1-5 were as described in M aterials and M ethods and the legend to Fig. 1. (C) Siah-1 protein lacking amino-terminal U bc-binding sequences forms a complex with DCC in cells. CHO cells were transfected with vectors encoding the indicated proteins. The pcDN A3 construct for the FLAG epitope-tagged, truncated Siah-1 (i.e., FLAG-Siah1 1 ) has the FLAG peptide tag MDYKDDDDK fused to amino acids 77-282 of Siah-1. Lysates were prepared $48 \mathrm{hr}$ after transfection, and a portion of the lysate was used for immunoprecipitation with DCC polyclonal antibody 645, directed against the DCC extracellular domain. The lysates (Ianes 1-4) and immunoprecipitates (lanes 5-8) were el ectrophoresed and ECL-Western blotting was carried out with a monoclonal antibody against the extracellular domain of DCC or against the FLAG epitope. Siah-1 coprecipitated with full-length DCC (DCC-FL) (lane 5) but not with a truncated form of DCC (DCC-T), lacking the DCC cytopl asmic domain (lane 8). The mobilities of molecular weight standards and the DCC and FLAG-Siah1 $\Delta$ proteins are indicated. 


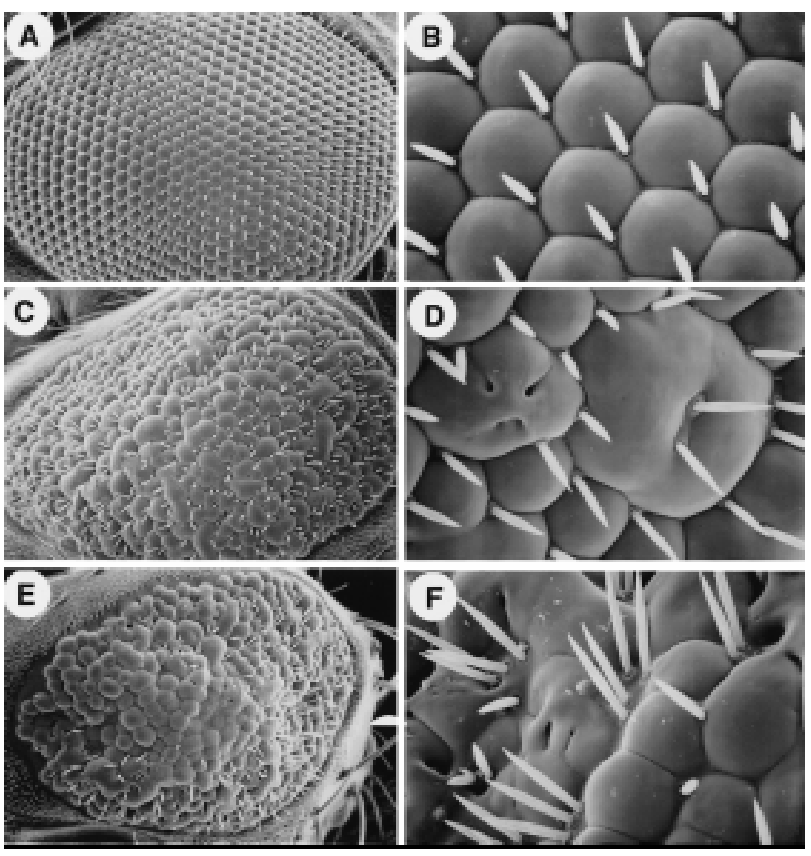

Figure 8. Ectopic expression of human DCC in the Drosophila eye causes rough eye phenotypes. Full-length human DCC cDN A coding sequence were expressed in transgenic flies under the transcriptional control of Drosophila sev promoter and enhancer elements. Shown are low (left panels) and high (right panels) power scanning electron micrographs of adult Drosophila eyes: Wild type (A,B); $2 \times$ sev-DCC (C,D); $4 \times$ sev-DCC $(\mathrm{E}, \mathrm{F})$.

the developing eye might interfere with Sina function and cause the R7 defects observed in the sev-DCC flies. To test this proposal di rectly, we generated $2 \times$ sev-DCC flies that also had one copy of sev-sina (in addition to their two functional endogenous sina alleles). Eyes of sev-sina flies had no morphological defects (data not shown). In contrast to the absence of $\mathrm{R} 7$ cells in $\sim 10 \%$ of the ommatidia of the $2 \times$ sev-DCC flies, we found that only $\sim 2 \%$ of ommatidia lacked R7 when the sev-sina transgene was also present (Fig. 9G,H). Three independent eyes were counted for each genotype to determine the effects on R7 formation in the $2 \times$ sev-DCC ( 451 total ommati dia) and the $2 \times$ sev-DCC, $1 \times$ sev-sina flies (581 total ommatidia). Overall eye roughness and the ommatidial fusion and orientation defects were not affected significantly by increased expression of sina (Fig. 9; data not shown), suggesting that some eye defects in the sevDCC flies likely reflect interaction of DCC with other signaling pathways. N onethel ess, the transgenic fly data support further that the in vivo relevance of the interaction between the DCC and Sina/Siah proteins.

\section{Discussion}

Recent findings have implicated DCC as a receptor or coreceptor for netrin-1 and have highlighted the important role of netrins, DCC, and DCC-related proteins in the development of the nervous system (Chan et al. 1996; Keino-Masu et al. 1996; Kolodziej et al. 1996; Serafini et al. 1996; Fazeli et al. 1997; Kolodziej 1997). The studies presented here were undertaken with the goal of identifying proteins that regulate DCC or transduce signals through its cytoplasmic domain. As a result of these investigations, we have obtained considerable evidence that Sina/Siah proteins regulate DCC via the ubiquitinproteasome pathway.

Sina was first identified because its inactivation causes the R 7 cell to adopt a cone (non-neuronal) cell fate (Carthew and Rubin 1990). Expression of the sina gene has been detected in various Drosophila cell types, and sina mutations also cause other phenotypes (Carthew and Rubin 1990). The role of Sina in R7 development is much better understood than its role in other cell types, and genetic experiments indicate that Sina functions

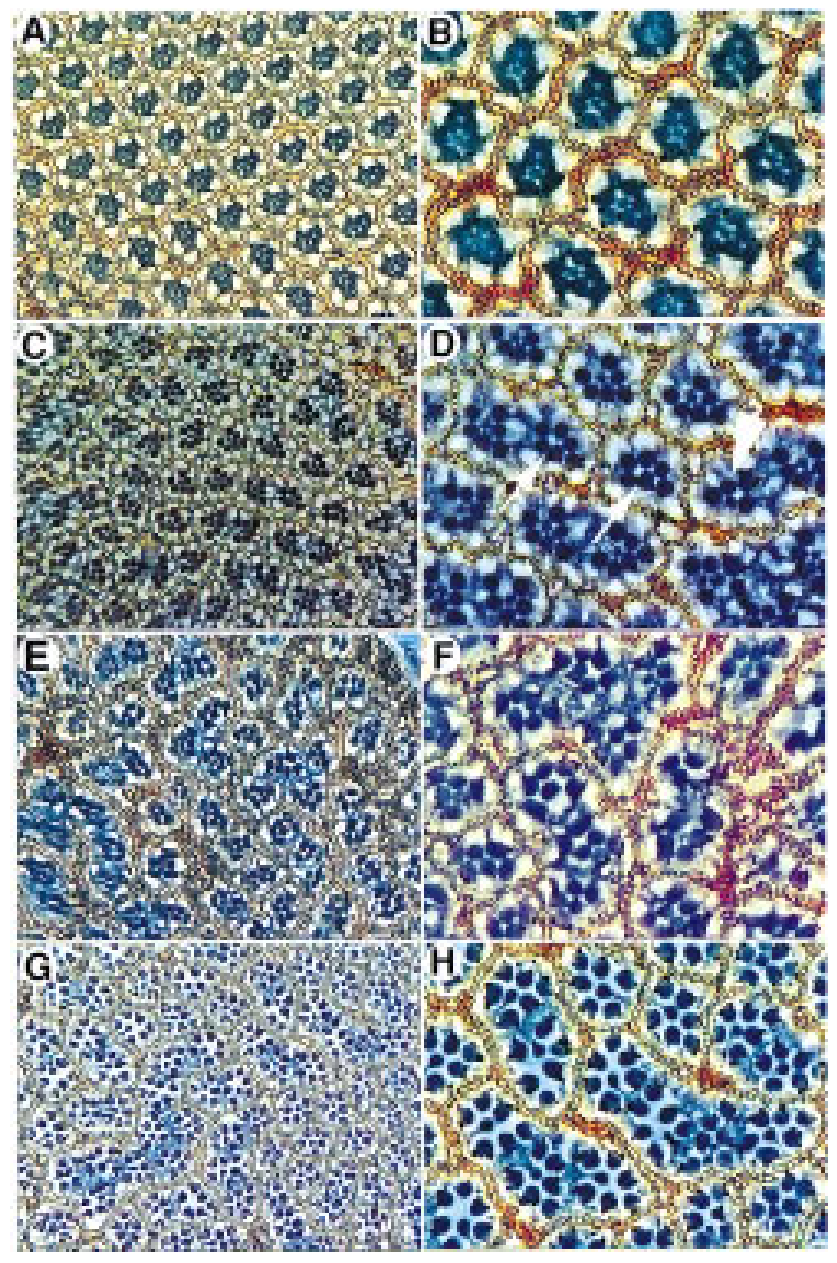

Figure 9. Ommatidial defects are seen in apical retinal sections from sev-DCC flies. Low power (left panels) and high power (right panels) images of apical retinal sections from flies with various genotypes are shown: Wild type (A,B); $2 \times$ sev-DCC $(C, D) ; 4 \times \operatorname{sev}-D C C(E, F)$; and $2 \times$ sev-DCC, $1 \times$ sev-sina $(G, H)$. Ommatidia with $\mathrm{R} 7$ photoreceptor cells missing are indicated by white arrows in D; the arrowhead indicates an ommatidia missing an outer photoreceptor cell. 
downstream of defined components of the sev pathway, including Ras, Raf, and MAPK (Fortini et al. 1992; Lai and Rubin 1992; Brunner et al. 1994; Chang et al. 1994; Chang et al. 1995; Dickson et al. 1995). For example, Ioss-of-function mutations in sina inhibit activated Ras, MAPK, or ectopically expressed phyllopod (PHYL) from inducing $\mathrm{R} 7$ devel opment. Recent data suggest that only ttk, which encodes a zinc finger transcription factor, functions downstream of sina (Lai et al. 1996; Yamamoto et al. 1996). No specific cellular function of Sina was known previously.

Cellular proteins targeted for degradation by the proteasome are modified covalently by the attachment of ubiquitin, which is linked to the $\epsilon$-amino group of one or more lysines of the target protein in a multi-step process involving several key proteins, including an E1 ubiquitin-activating enzyme, an E2 U bc, and often an E3 ubiquitin-protein ligase (Ciechanover 1994; Goldberg 1995). U biquitinated and polyubiquitinated proteins are recognized and proteolyzed by the proteasome, a large ATPdependent protease complex. The specific means by which the Sina/Siah proteins promote DCC degradation via the ubiquitin-proteasome pathway has not yet been defined. However, we have demonstrated that Sina/Siah proteins interact in yeast via their amino-terminal sequences with Ubc9 homologs. Moreover, mutant Siah proteins lacking these amino-terminal sequences complexed stably with DCC in cells, but failed to promote its degradation.

The processes of ubiquitination and deubiquitination have been implicated previously in neural development and $\mathrm{R} 7$ fate specification. The Drosophila bendless (ben) gene has an important role in synaptic connectivity (M uralidhar and Thomas 1993; Oh et al. 1994). Defects in ben mutants include al tered morphology of photoreceptor neurons, abnormal projections of the R7 and R8 axons, as well as deformation of the R 7 cell. ben encodes a protein with significant similarity to $U$ bc proteins, including Ubc9 homologs. Inactivation of the fat facets gene results in supernumerary $\mathrm{R} 7$ formation (FischerVize et al. 1992). Intriguingly, fat facets encodes a protein that can cleave ubiquitin from ubiquitin-protein conjugates, presumably inhibiting the degradation of specific proteins that repress $\mathrm{R} 7$ fate determination (Huang et al. 1995).

As noted above, Sina is expressed in a number of Drosophila tissues and its inactivation leads to other phenotypes besides $\mathrm{R} 7$ loss, including defects in sensory bristle formation, a 10-fold reduction in adult lifespan, generally lethargic and uncoordinated adult behavior, and infertility in males and females (Carthew and Rubin 1990). Mammalian Siahs are conserved extremely well with Sina, with upward of $85 \%$ amino acid identity, and Siahs are expressed at low levels in many adult tissues (Della et al. 1993; N emani et al. 1996; Hu et al. 1997). In addition, DCC, DCC-related proteins, and netrins are expressed at reduced levels in many embryonic and adult tissues (Fearon et al. 1990; Choung et al. 1994; Kennedy et al. 1994; Pierceall et al. 1994a; Vielmetter et al. 1994; Chan et al. 1996; Kolodiej et al. 1996; Meyerhardt et al.
1997; Kolodiej 1997). Therefore, the interaction between Sina and DCC may be important in modulating DCC function in a variety of tissues, perhaps regulating the migration and/or differentiation of cells in response to netrin cues. Additional studies of the Sina/Siah proteins and the proteins they regulate are likely to further our understanding of the means by which the ubi quitin-proteasome degradation pathway regulates cell fate decisions in the developing eye and other tissues.

\section{Materials and methods}

\section{Molecular biology}

Yeast two-hybrid plasmid constructs The pPC97-CYH2 and the pPC 86 plasmids (Chevray and N athans 1992; Du et al. 1996; Vidal 1997) encode the DN A-binding domain (amino acids 1147) and the transcriptional activation domain (amino acids 768-881) of yeast GAL4, as well as LEU 2 and TRP1 selectable markers, respectively. All DN A-binding domain and transcriptional acitivation domain fusions were generated by cloning CDNA fragments in-frame downstream of the DNA-binding or transcriptional activation domains, and constructs were confirmed by sequencing and/or fusion protein expression and interaction studies. The DNA-binding fusions (pPC97) include pPC 97-DCC cyto (DCCcyto), amino acids 1120-1447 of DCC; pPC 97-DCC cyto $\triangle 1$ (DCC1), amino acids $1120-1189$ of DCC; pPC97-DCC cyto $\triangle 2$ (DCC2), amino acids $1120-1259$ of DCC; pPC97-DCC cyto $\triangle 3$ (DCC3), amino acids 1120-1325 of DCC; pPC 97-DCC cyto $\Delta 4$ (DCC4), amino acids 1120-1392 of DCC; pPC 97-DCC cyto 7 (DCC 7), amino acids 1156-1364 of DCC; pPC97-DCC cyto $\Delta 8$ (DCC8), amino acids 1203-1392 of DCC; pPC97-Neo, amino acids 1128-1461 of human neogenin; pPC97-NeoT, amino acids 1128-1407 of neogenin; pPC97$\mathrm{N} \mathrm{eoS}$, amino acids 1128-1249/1303-1461 of the spliced form of human neogenin; pPC97-N eoS-T, amino acids 1128-1249/ 1303-1407 of the spliced form of neogenin; pPC97-Rb, amino acids 302-928 of pRb (19); pPC97-cFos, amino acids 132-211 of cFos (13); pPC97-dE2F, amino acids 342-437. The activation domain fusions (pPC 86-) include pPC 86-Sina, amino acids 1314 of Sina (6); pPC86-SinaT, amino acids 115-314 of Sina; pPC 86-hSiah1, amino acids 1-282 of human Siah-1; pPC86hSiah2, amino acids 1-324 of human Siah-2; pPC 86-hSiah2 $\Delta 1$, amino acids 103-324 of human Siah-2; pPC 86-hSiah2 2 2, amino acids 103-287 of human Siah-2; pPC 86-hSiah2 $\Delta 4$, amino acids 198-324 of human Siah-2; pPC86-mSiah-2 , amino acids 115325 of mouse Siah-2; pPC 86-HUBC9, amino acids 1-158 of human UBC9; pPC86-Dubc, full-coding region of Drosophila UBC 9; pPC 86-E2F1, amino acids 159-437 of E2F1; pPC86-Jun, amino acids 250-334 of Jun (13); pPC86-dDP, amino acids 1410 of DP-1 (18).

S2 expression constructs The Drosophila heat shock-inducible vector $\mathrm{pC}$ aSpeR-hs and metallothionein-inducible vector pMT (Busseau et al. 1994) were gifts from Spyros ArtavanisTsakonas and were used to generate Sina and DCC expression constructs, respectively. Amino-terminal c-M yc epitope-tagged Sina (amino acids 2-314) and SinaT (amino acids 2-199) CDN A fragments were generated by PCR and cloned into the EcoRI and Xbal sites of the $\mathrm{pCaSpeR-hs}$ vector ( $\mathrm{pC}$ aSpeR-hs-SinaN M yc and pCaSpeR-hs-SinaT N M yc). The carboxy-terminal vesicular stomatitis virus glycoprotein (VSVG) epitope-tagged human DCC cytoplasmic domain was inserted into pMT at EcoRI-Sall site to construct pMT-DCCcyto. A 3.4-kb Xhol-BamHI frag- 
ment of DCC CDNA was cloned into PMT-DCCcyto to generate a full-length DCC cDNA in pMT (pMT-DCC). pMT-DCCcytoT was made by deleting the EcoRV-Clal $0.5-\mathrm{kb}$ fragment from pMT-DCC cyto. The sequences of all vectors generated by PCR were verified.

Mammalian expression constructs The mammalian expression vector pcDNA3 (Invitrogen, San Diego, CA) was used to generate Sina and Siah expression constructs. To generate fulllength sense and antisense $\mathrm{SIAH}-1$ and $\mathrm{SI} A \mathrm{H}-2$ expression constructs (pcDNA3-Siah1, pcDNA3-Siah2 and pcDNA3-Siah2AS), a 2.2-kb EcoRI-EcoRI cDN A fragment of human siah-2 and a 2.0-kb EcoRI-EcoRI cDNA fragment of human siah-1 were cloned into pcDNA3. Constructs encoding truncated forms of human Siah-2 [pcDN A3-Siah2- $\Delta(A, B, C, D)]$, were obtained by cloning of SIAH-2 CDNA fragments (amino acids 118-324, amino acids 118-287, amino acids 118-231, amino acids 1-23, and 72-231, respectively) into EcoRI-Xbal sites of pcDN A3. The pCDNA3 construct encoding the FLAG epitope-tagged mutant form of Siah-1 (i.e., FLAG-Siah1 $1 \Delta$ ) was generated by removal of the first 76 amino acids of Siah-1 and introduction of the FLAG peptide tag MDYKDDDDK upstream of amino acid 77. pcDNA3-SinaNMyc and pcDNA3-SinaTNMyc were constructed by subcloning the corresponding EcoRI-Xbal fragments from pCaSpeR-hs-SinaNMyc and pCaSpeR-hsSinaTNMyc into pcDNA3. Constructs encoding full-length DCC (DCC-FL) and a cytoplamic truncated form (DCC-T) have been described (Pierceall et al. 1994b). The ubiquitin expression construct encoding a $\mathrm{His}_{6}-$, c-Myc-tagged yeast ubiquitin was kindly provided by Dr. Ron R. Kopito (Ward et al. 1995).

Drosophila P-element sev-DCC construct A full-length human DCC cDNA fragment obtained from pBSII-DCC was inserted into Clal-Xbal sites downstream of fly sev promoter cassette in pSP/HSS. The sev promoter/DCC fusion was then cloned into the Notl site in the sev enhancer construct pSE8/ DM 30. Details of the sev promoter/enhancer constructs are described in Dickson et al. (1992).

cDNA libraries The Glio I cDNA library in the pPC86 vector was prepared using mRN A from human gl ioblastoma xenograft specimens kindly provided by Dr. Sandra Bigner. Three different tumor specimens with high (656), moderate (643), and absent (542) DCC expression (Ekstrand et al. 1995) were used, and mRN A was prepared from 0.2 grams of each tumor sample with the Micro Fast Track mRN A isolation kit (Invitrogen). cDN A was synthesized using $\mathrm{N}$ otl-poly(dT) primers and was blunt end ligated to Sall adaptors, using the SuperScript plasmid system for CDNA synthesis and cloning (GIBCO BRL/Life Technologies, Grand Island, NY). After digestion with Notl, cDN As were size-sel ected and ligated into pPC 86 at Sall-Notl site. Approximately $1.2 \times 10^{6}$ independent transformants were obtained, amplified, and used for DN A isolation from the Glio I library. The Alala I library was generated from polyA-sel ected RN A from 12to 13-day whole murine fetuses. CDNAs were cloned into the EcoRI and Spel sites of pPC86, using methods similar to those described above for the Glio I library. The library had a complexity of roughly $3.0 \times 10^{6}$ independent clones prior to amplification. The Drosophila SL2 library has been described (Du et al. 1996). To isolate full-length human siah-1 and siah-2 CDN As, a human fetal brain cDN A library constructed in the $\lambda$ Zap phage vector was purchased from Stratagene (La Jolla, CA ). Approximately $1.5 \times 10^{6}$ plaques were screened with a mouse siah-2 cDN A fragment, obtained from the two-hybrid screen, as probe. Filters were lifted and hybridized with radiolabeled probe using standard techniques. Plasmids were rescued from the $\lambda$ Zap phage by in vivo excision with $F_{1}$ helper phage (Stratagene).

Yeast two-hybrid studies

All two-hybrid studies were performed with the yeast strain MaV103 (Du et al. 1996; Vidal 1997) and transformation was performed using the standard lithium acetate method. Transformants were first plated onto synthetic complete (SC)-LeuTrp plates, followed by replica plating onto SC-Leu-Trp-His plates containing $20 \mathrm{~mm}$ 3-AT after 2 days. Yeast colonies growing out after additional 3-4 days of incubation were picked as primary positives and further tested in three reporter assays: (1) growth on SC-Leu-Trp-His plates supplemented with $20 \mathrm{~mm}$ 3-AT; (2) $\beta$-gal actosidase activity; and (3) URA3 activation on SC-Leu-Trp plates containing $0.2 \%$ 5-fluoro-orotic acid (5-FOA), as a counterselection method (Vidal 1997). Activation domain plasmids were rescued from the sel ected positive transformants after all three tests. M aV103 cells were retransformed with either rescued activation domain plasmid and the DNAbinding domain fusion or rescued activation domain plasmid and the pPC97-CYH2 vector without a CDNA insert as a control. Activation domain plasmids, repeatedly positive in all three reporter assays, recovered and sequenced either manually or with the automated Applied Biosystems, Inc. system.

\section{Cell culture and DNA transfection}

Drosophila SL2 cells were grown as described (Fehon et al 1990). Transfection of $1 \times 10^{6}$ cells $/ \mathrm{ml}$ was carried out in 6-well plates with $10 \mu \mathrm{g}$ of plasmid DN A and Lipofectin (GIBCO BRL). Protein expression was induced with $0.7 \mathrm{~mm} \mathrm{CuSO}_{4}$ and two to three rounds of heatshock, as described (Diederich et al. 1994). COS-1 cells obtained from the American Type Culture Collection (ATCC, Rockville, MD) were maintained in Dulbecco's M odified Eagle medium (DM EM) supplemented with $10 \%$ fetal bovine serum (FBS) and antibiotics. $\mathrm{CHO}$ cells were obtained from the ATCC and grown in MEM $\alpha$ medium plus $10 \%$ FBS and antibiotics. Mammalian cell transfections were carried out by using Opti-MEM reduced serum medium and LipofectAmine reagent, as described by the manufacturer (GIBCO BRL).

\section{In vitro binding assay}

All GST-DCC fusions were constructed in the PGX-2TK vector (Pharmacia Biotech, U ppsala, Sweden), and verified by sequencing. The construct for the GST-p16 (human p16 cyclin kinase inhibitor) fusion protein was kindly provided by Dr. Joseph Germino (Yale University, N ew Haven, CT). GST fusion proteins were expressed and purified as described (Reale et al. 1994). COS-1 cells were transfected with pcDNA3-SinaNMyc or pcDN A3-SinaT N M yc. Forty-eight hours after transfection, the cells were lysed with TBS-Triton lysis buffer (Tris-buffered saline at $\mathrm{pH} 8.0,1 \%$ Triton, $10 \mu \mathrm{g} / \mathrm{ml}$ of PMSF, $50 \mu \mathrm{g} / \mathrm{ml}$ of antipain, $5 \mu \mathrm{g} / \mathrm{ml}$ of aprotinin, $2 \mu \mathrm{g} / \mathrm{ml}$ of leupeptin). In vitro binding assays were performed by mixing $10 \mu \mathrm{g}$ of GST fusion proteins with cell lysate and incubated with $15 \mu$ l of glutathione-Sepharose beads (Pharmacia Biotech, U ppsala, Sweden) in $500 \mu$ of TBS-Triton buffer supplemented with $1 \%$ BSA at $4^{\circ} \mathrm{C}$ for $4 \mathrm{hr}$ with agitation. After incubation, the mixtures were pelleted, and the pellets were washed with cold TBS-Triton Iysis buffer three times. Bound proteins recovered from the beads were separated by SDS-PAGE. After semi-dry transfer (Transblot, Bio-Rad, Hercules, CA) to Immobilon (Millipore, Bedford, MA) membranes, c-M yc epitope-tagged Sina proteins 
were detected by Western blotting with an anti-M yc monoclonal antibody MYC1-9E10.2 (ATCC) and enhanced chemiluminescence (ECL).

\section{Western blot and immunoprecipitation studies}

COS-1 or CHO cells were cotransfected with pCM V-DCC-FL or PCMV-DCC-T constructs and pCDNA3-Sina/Siah constructs or pcDN A 3 al one using cationic liposomes (LipofectAMIN E reagent, GIBCO/BRL). Approximately $48 \mathrm{hr}$ after transfection, cells were lysed in $0.1 \% \mathrm{~N} \mathrm{P}-40$ buffer containing $50 \mathrm{~mm}$ HEPES (pH 7.2), $250 \mathrm{~mm} \mathrm{NaCl}, 10 \%$ glycerol, $2 \mathrm{~mm}$ EDTA and protease inhibitors $(50 \mu \mathrm{g} / \mathrm{ml}$ of antipain, $5 \mu \mathrm{g} / \mathrm{ml}$ of aprotinin, $2 \mu \mathrm{g} / \mathrm{ml}$ of leupeptin and $10 \mu \mathrm{g} / \mathrm{ml}$ of phenylmethylsulfonyl fluoride). Cell lysates were separated by SDS-PAGE and transferred to Immobilon membranes (Millipore) followed by ECL-Western blot analysis with DCC polycl onal (Real e et al. 1994) and monoclonal antibodies (G97-449 and G92-13, PharM ingen, San Diego, CA). DCC proteins were immunoprecipitated with polyclonal antibody 645 or by combination of DCC polyclonal antibodies 645 and 723 (Reale et al. 1994). A polyclonal antibody against $\mathrm{Na}^{+} / \mathrm{K}^{+}$ATPase (Research Diagnostics, Inc., Flanders, NJ) was used to verify loading of Western blots.

\section{Immunofluorescence studies}

Transfected and induced S2 cells were collected by gentle centrifugation and fixed in $250 \mu \mathrm{l}$ of freshly prepared $2 \%$ paraformaldehyde/PBS for $15 \mathrm{~min}$ at room temperature. Fixed cells were pelleted gently and washed with PBS twice, followed by staining with primary antibodies (1:25 dilution of anti-Myc mouse monoclonal antibody 9E10.2; $5 \mu \mathrm{g} / \mathrm{ml}$ of rabbit anti-DCC antisera 723 or 645; Reale et al. 1994) in PBS with $0.1 \%$ saponin (Sigma, St. Louis, MO) and 1\% normal goat serum (Pocono Rabbit Farm, Canadensis, PA) for 1 hr. Subsequently, cells were rinsed twice with PBS and stained with Texas red-conjugated goat anti-rabbit and FITC-conjugated goat anti-mouse antibodies (double-labeling grade, Jackson ImmunoResearch Laborataries, Inc.) for $1 \mathrm{hr}$ in the dark. Cells were rinsed with PBS twice and mounted onto glass slides after resuspension in $90 \%$ glycerol, $100 \mathrm{~mm}$ Tris at pH 8.0, and 0.5\% N-propyl gallate (Sigma). Confocal images were obtained from the Bio-Rad M RC 500 laser scanning confocal system connected to a Zeiss Axiovert compound microscope as described (Fehon et al. 1990; Diederich et al. 1994). Pseudocoloring was performed using the Adobe Photoshop software program.

\section{Drosophila studies}

Fly cultures and crosses were performed according to standard procedures. Embryos were injected with the sev-DCC P-element constructs and four sev-DCC transformant lines were established (Spradling and Rubin 1982). Scanning el ectron microscopy studies were performed as described (Xu and ArtavanisTsakonas 1990). For retinal section studies, fly eyes were fixed and sectioned according to Tomlinson and Ready (1987) and viewed under phase-contrast optics on a Zeiss Axiphot microscope.

\section{Acknowledgments}

We thank Dr. Spyros-Artavanis and his laboratory members for plasmid reagents, advice, and encouragement; Dr. Ron R. Kopito for providing the c-M yc-tagged ubiquitin expression vector; Drs. Gary Nabel and Ross Stein (Proscript, Inc.) for providing MG132; Drs. Ed Harlow and Wei Du for assistance with the two-hybrid studies; Dr. Gerald Rubin for providing sev-sina transgenic flies; and Drs. Kathleen R. Cho, Elizabeth M. Petty, Robert M. Strieter, Bert Vogelstein, David Ginsburg, and Gary $\mathrm{N}$ abel for comments on the manuscript. This work was supported by grant CA 70097 to E.R.F.

The publication costs of this article were defrayed in part by payment of page charges. This article must therefore be hereby marked "advertisement" in accordance with 18 USC section 1734 solely to indicate this fact.

\section{References}

Brunner, D., N. Oellers, J. Szabad, W.H. Biggs III, S.L. Zipursky, and E. Hafen. 1994. A gain of function mutation in Drosophila M AP kinase activates multiple receptor tyrosine kinase signaling pathways. Cell 76: 875-888.

Busseau, I., R.J. Diederich, T. Xu, and S. Artavanis-Tsakonas. 1994. A member of the $\mathrm{N}$ otch group of interacting loci, deltex, encodes a cytoplasmic basic protein. Genetics 136: 585596.

Carthew, R.W. and G.M. Rubin. 1990. seven in absentia, a gene required for specification of $\mathrm{R} 7$ cell fate in the Drosophila eye. Cell 63: 561-577.

Cavenee, W.K., T.P. Dryja, R.A. Phillips, W.F. Benedict, R. Godbout, G.L. Gallie, A.L. Murphree, L.C. Strong, and R.L. White. 1983. Expression of recessive allel es by chromosomal mechansims in retinoblastoma. N ature 305: 779-784.

Chan, S.S.-Y., H. Zheng, M.-W. Su, R. Wilk, M.T. Killeen, E.M. Hedgecock, and J.G. Culotti. 1996. UN C-40, a C. elegans homolog of DCC (del eted in colorectal cancer), is required in motile cells responding to UN C-6 netrin cues. Cell 87: 187195.

Chang, H.C., F.D. Karim, E.M. O'N eoill, I. Rebay, N.M. Solomon, M. Therrien, D.A. Wassarman, T. Wolff, and G.M.Rubin. 1994. Ras signal transduction pathway in Drosophila eye development. Cold Spring Harbor Symp. Quant. Biol. 59: 147-153.

Chang, H.C., N.M. Solomon, D.A. Wassarman, F.D. Karim, M. Therrien, G.M. Rubin, and T. Wolff. 1995. phyllopod functions downstream of Rasl in the fate determination of a subset of photoreceptors in Drosophila. Cell 80: 1-20.

Chevray, P.M., and D. N athans. 1992. Protein interaction cloning in yeast: Identification of mammalian proteins that react with the leucine zipper of Jun. Proc. Natl. Acad. Sci. 89: 5789-5793.

Cho, K.R. and E.R. Fearon. 1995. DCC: Linking tumor suppressor genes and altered cell surface interactions in cancer? Curr. Opin. Genet. Dev. 5: 72-78.

Cho, K.R., J.D. Oliner, J.W. Simons, L. Hedrick, E.R. Fearon, A.C. Preisinger, P. Hedge, G.A. Silverman, and B. Vogel stein. 1994. The DCC gene-structural analysis and mutations in colorectal carcinomas. Genomics 19: 525-531.

Chuong, C.M., T.X. Jiang, E. Yin, and R.B. Widelitz. 1994. CDCC (chicken homologue to a gene deleted in colorectal carcinoma) is an epithelial adhesion molecule expressed in the basal cells and involved in epithelial-mesenchymal interaction. Dev. Biol. 164: 383-397.

Ciechanover, A. 1994. The ubiquitin-proteasome proteolytic pathway. Cell 79: 13-21.

Cooper, H.M., P. Armes, J. Britto, J. Gad, and A.F. Wilks. 1995. Cloning of the mouse homol ogue of the del eted in col orectal cancer gene $(\mathrm{mDCC})$ and its expression in the developing mouse embryo. Oncogene 11: 2243-2254.

Della, N.G., P.V. Senior, and D.L. Bowtell 1993. Isolation and characterization of murine homologues of the Drosophila 
seven in absentia gene (sina). Devel opment 117: 1333-1343.

Dickson, B., F. Sprenger, D. Morrison, and E. Hafen. 1992. Raf functions downstream of Ras1 in the Sevenless signal transduction pathway. Nature 360: 600-603.

Dickson, B., M. Dominguez, A. van der Straten, and E. Hafen. 1995. Control of Drosophila photoreceptor cell fates by Phyllopod, a novel nuclear protein acting downstream of the Raf kinase. Cell 80: 453-462.

Diederich, R.J, K. M atsuno, H. Hing, and S. Artavanis-T sakonas. 1994. Cytosolic interaction between deltex and $\mathrm{N}$ otch ankyrin repeats implicates del tex in the $\mathrm{N}$ otch signaling pathway. Development 120: 473-481.

Du, W., M. Vidal, J.-E. Xie, and N. Dyson. 1996. A homolog of the retinoblastoma family of proteins regulates E2F activity in Drosophila. Genes \& Dev. 10: 1206-1218.

Ekstrand, B.C., T.A. Mansfield, S.H. Bigner, and E.R. Fearon. 1995. DCC expression is al tered by multiple mechanisms in brain tumors. Oncogene 11: 2393-2402.

Fazeli, A., S.L. Dickinson, M.L. Hermiston, R.V. Tighe, R.G. Steen, C.G. Small, E.T. Stoeckli, K. Keino-M asu, M. M asu, H. Rayburn, J. Simons, R.T. Bronson, J.I. Gordon, M. TessierLavigne, and R.A. Weinberg. 1997. Phenotype of mice lacking functional Deleted in colorectal cancer (Dcc) gene. $\mathrm{Na}$ ture 386: 796-804.

Fearon, E.R. 1996. DCC: Is there a connection between tumorigenesis and cell guidance molecules? Biochem. Biophys. Acta 1288: M 17-M 23.

Fearon, E.R., K.R. Cho, J.M. Nigro, J.M., S.E. Kern, J.W. Simons, J.M. Ruppert, S.R. Hamilton, A.C. Preisinger, G. Thomas, K.W. Kinzler, and B. Vogelstein. 1990. Identification of a chromosome $18 \mathrm{q}$ gene that is altered in colorectal cancers. Science 247: 49-56.

Fehon, R.G., P.J. Kooh, I. Rebay, C.L. Regan, T. Xu, A.T. Muskavitch, and S. Artavanis-Tsakonas. 1990. Molecular interactions between the protein products of neurogenic loci $\mathrm{N}$ otch and Delta, two EGF-homologous genes in Drosophila. Cell 61: 523-534.

Fields, S. and O. Song. 1989. A novel genetic system to detect protein-protein interactions. Nature 340: 245-246.

Fortini, M.E., M.A. Simon, and G.M. Rubin. 1992. Signaling by the sevenless protein tyrosine kinase is mimicked by Ras1 activation. Nature 355: 559-561.

Fischer-Vize, J.A., G.M. Rubin, and R. Lehmann. 1992. The fat facets gene is required for Drosophila eye and embryo development. Development 116: 985-1000.

Goldberg, A.L. 1995. Functions of the proteasome: The lysis at the end of the tunnel. Science 268: 522-523.

Hedrick, L., K.R. Cho, E.R. Fearon, T.C. Wu, K.W. Kinzler, and B. Vogelstein. 1994. The DCC gene product in cellular differentiation and colorectal tumorigenesis. Genes \& Dev. 8: 1174-1183.

Hu, G., Y.-L. Chung, T. Glover, V. Valentine, A.T. Look, and E.R. Fearon. 1997. Characterization of human homologs of the Drosophila seven in absentia (sina) gene. Genomics (in press).

Huang, Y., R.T. Baker, and J.A. Fischer-Vize. 1995. Control of cell fate by a deubiquitinating enzyme encoded by the fat facets gene. Science 270: 1828-1831.

Itoh, F., Y. Hinoda, M. Ohe, Y. Ohe, T. Ban, T. Endo, K. Imai, and A. Yachi. 1993. Decreased expression of DCC mRNA in human colorectal cancers. Int. J. Cancer 53: 260-263.

Keino-Masu, K., M. Masu, L.Hinck, E.D. Leonardo, S.S.-Y. Chan, J.G. Culotti, and M. Tessier-Lavigne. 1996. Deleted in colorectal cancer (DCC) encodes a netrin receptor. Cell 87: 175-185.

Kennedy, T.E., T. Serafini, J.R. de la Torre, and M. Tessier-
Lavigne. 1994. N etrins are diffusi ble chemotropic factors for commissural axons in the embryonic spinal cord. Cell 78: 425-435.

Knudson, A.G. 1993. Antioncogenes and human cancer. Proc. Natl. Acad. Sci. 90: 10914-10921.

Kolodziej, P.A. 1997. DCC's function takes shape in the nervous system. Curr. Opin. Genet. Dev. 7: 87-92.

Kolodziej, P.A., L. Timpe, K.J. Mitchell, C.S. Goodman, S.R. Fried, L.Y. Jan, and Y.N. Jan. 1996. frazzled encodes a member of the immunoglobulin subfamily and is required for CN S axon guidance and motor axon targeting. Cell 87: 197204.

Kovalenko, O.V., A.W. Plug, T. Haaf, D.K. Gonda, T. Ashley, D.C. Ward, C.M. Radding, and E.I. Golub. 1996. M ammalian ubiquitin-conjugating enzyme Ubc9 interacts with Rad51 recombination protein and localizes in synaptonemal complexes. Proc. Natl. Acad. Sci. 93: 2958-2963.

Lai, Z.-C. and G.M. Rubin. 1992. N egative control of photoreceptor development in Drosophila by the product of the yan gene, an ETS domain protein. Cell 70: 609-620.

Lai, Z.-C., S.D. Harrison, F. Karim, Y. Li, and G.M. Rubin. 1996. Loss of tramtrack gene activity results in ectopic R7 cell formation, even in a sina mutant background. Proc. Natl. Acad. Sci. 93: 5025-5030.

Lawlor, K. and R. N arayanan. 1992. Persistent expression of the tumor suppressor gene DCC is essential for neuronal differentiation. Cell Growth Diff. 3: 609-616.

Meyerhardt, J.A., A.T. Look, S.H. Bigner, and E.R. Fearon. 1997. Identification and characterizaation of neogenin, a DCC-related gene. Oncogene 14: 1129-1136.

Muralidhar, M.G. and J.B. Thomas. 1993. The Drosophila bendless gene encodes a neural protein related to ubiquitin-conjugating enzymes. Neuron 11: 253-266.

N emani, M., G. Linares-Cruz, H. Bruzzoni-Giovanelli, J.-P. Roperch, M. Tuynder, L. Bougueleret, D. Cherif, M. M edhioub, P. Pasturaud, V. Alavaro, et al. 1996. Activation of the human homol ogue of the Drosophila sina gene in apoptosis and tumor suppression. Proc. Natl. Acad. Sci. 93: 9039-9042.

Oh, C.E., R. McMahon, S. Benzer, and M.A. Tanouye. 1994. bendless, a Drosophila gene affecting neuronal connectivity encodes a ubiquitin-conjugating enzyme homolog. J. Neuroscience 14: 3166-3179.

Palombella, V.J., O.J. Rando, A.L. Goldberg, and T. Maniatis. 1994. The ubiquitin-proteasome pathway is required for processing the NF-кB1 precursor protein and the activation of NF-кB. Cell 78: 773-785.

Pierceall, W.E., M.A. Reale, A.F. Candia, C.V.E. Wright, K.R. Cho, and E.R. Fearon. 1994a. Expression of a homologue of the deleted in colorectal cancer (DCC) gene in the nervous system of devel oping Xenopus embryos. Dev. Biol. 166: 654665.

Pierceall, W.E., K.R. Cho, R.H. Getzenberg, M.A. Reale, L. Hedrick, B. Vogelstein, and E.R. Fearon. 1994b. NIH3T 3 cells expressing the del eted in col orectal cancer tumor suppressor gene product stimulate neurite outgrowth in rat PC 12 pheochromocytoma cells. J. Cell Biol. 124: 1017-1027.

Reale, M.A., G. Hu, A.I. Zafar, R.H. Getzenberg, S.M. Levine, and E.R. Fearon. 1994. Expression and al ternative splicing of the deleted in colorectal cancer (DCC) gene in normal and malignant tissues. Cancer Res. 54: 4493-4501.

Rock, K.L., C. Gramm, L. Rothstein, K. Clark, R. Stein, L. Dick, D. Hwang, and A.L. Goldberg. 1994. Inhibitors of the proteasome block the degradation of most cell proteins and the generation of peptides presented on M HC class I molecules. Cell 78: 761-777.

Saurin, A.J., K.L.B. Borden, M.N. Boddy, and P.S. Freemont. 
Hu et al.

1996. Does this have a familiar ring? Trends Biochem. Sci. 21: 208-214.

Serafini, T., S.A. Colamarino, E.D. Leonardo, H. Wang, R. Beddington, W.C. Skarnes, and M. Tessier-Lavigne. 1996. N etrin-1 is required for commissural axon guidance in the de veloping vertebrate nervous system. Cell 87: 1001-1014.

Seufert, W., B. Futcher, and S. Jentsch. 1995. Role of a ubiquitinconjugating enzyme in degradation of S- and M-phase cyclins. Nature 373: 78-81.

Shibata, D., M .A. Reale, P. Lavin, M. Silverman, E.R. Fearon, G. Steel J Jr., J.M. Jessup, M. Loda, and I.C. Summerhayes. 1996. The DCC protein and prognosis in colorectal cancer. N. Eng. J. Med. 335: 1727-1732.

Spradling, A.C. and G.M. Rubin. 1982. Transposition of cloned $P$ elements into Drosophila germ line chromosomes. Science 218: 341-347.

Thiagalingam, S., C. Lengauer, F.S. Leach, M. Schutte, S.A. Hahn, J. Overhauser, J.K.V. Willson, S. Markowitz, S.R. Hamilton, S.E. Kern, K.W. Kinzler, and B.Vogelstein. 1996. Evaluation of candidate tumour suppressor genes on chromosome 18 in colorectal cancers. Nature Genet. 13: 343346.

Tomlinson, A. and D.F. Ready. 1987. Cell fate in Drosophila ommatidium. Dev. Biol. 123: 264-275.

Varskavsky, A. 1992. The N-end rule. Cell 69: 725-735.

Vidal, M. 1997. The reverse two-hybrid system. In The twohybrid system (ed. P. Bartel and S. Fiel ds). Oxford U niversity Press, N ew York. (In press).

Vielmetter, J., J.F. Kayyem, J.M. Roman, and W.J. Dreyer. 1994. $\mathrm{N}$ eogenin, an avian cell surface protein expressed during terminal neuronal differentiation is closely related to the human tumor suppressor molecule deleted in colorectal cancer. J. Cell Biol. 127: 2009-2020.

Ward, C.L., S. Omura, and R.R. Kopito. 1995. Degradation of CFTR by the ubiquitin-proteasome pathway. Cell 83: 121127.

Xu, T. and S. Artavanis-Tsakonas. 1990. deltex, a locus interacting with the neurogenic genes, notch, delta, and mastermind in Drosophila melanogaster. Genetics 126: 665-677.

Yamamoto, D., I. Nihonmatsu, T. Matsuo, H. Miyamoto, S. Kondo, K. Hirata, and Y. Ikegami. 1996. Genetic interactions of pokkuri with seven in absentia, tramtrack and downstream components of the sevenless pathway in R7 photoreceptor induction in Drosophila melanogaster. Roux's Arch. Dev. Biol. 205: 215-224. 


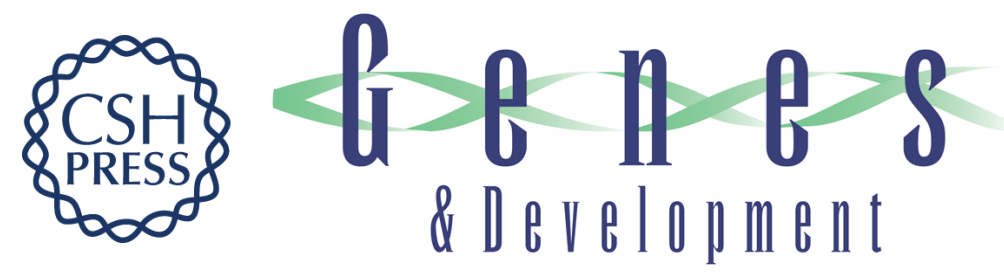

\section{Mammalian homologs of seven in absentia regulate DCC via the ubiquitin-proteasome pathway}

Gang $\mathrm{Hu}$, Sheng Zhang, Marc Vidal, et al.

Genes Dev. 1997, 11:

Access the most recent version at doi:10.1101/gad.11.20.2701

References This article cites 60 articles, 22 of which can be accessed free at: http://genesdev.cshlp.org/content/11/20/2701.full.html\#ref-list-1

License

Email Alerting

Receive free email alerts when new articles cite this article - sign up in the box at the top Service right corner of the article or click here.

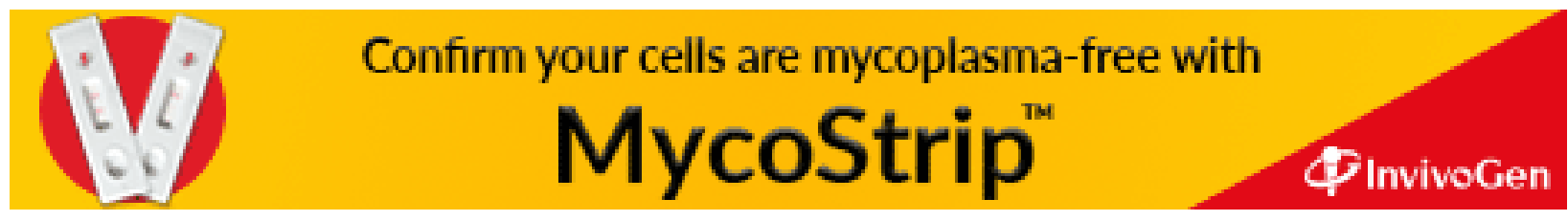

